\title{
An evaluation of processing InSAR Sentinel-1A/B data for correlation of mining subsidence with mining induced tremors in the Upper Silesian Coal Basin (Poland)
}

\author{
Artur Krawczyk ${ }^{1, *}$, Radostaw Grzybek ${ }^{1}$ \\ ${ }^{1}$ AGH University of Science and Technology, Faculty of Mining Surveying \& Environmental Engineering; Department of Mining Areas \\ Protection, Geoinformatics and Mining Surveying, al. A. Mickiewicza 30, 30-059 Krakow, Poland
}

\begin{abstract}
The Satellite Radar Interferometry is one of the common methods that allow to measure the land subsidence caused by the underground black coal excavation. The interferometry images processed from the repeat-pass Synthetic Aperture Radar (SAR) systems give the spatial image of the terrain subjected to the surface subsidence over mining areas. Until now, the InSAR methods using data from the SAR Systems like ERS-1/ERS-2 and Envisat-1 were limited to a repeat-pass cycle of 35-day only. Recently, the ESA launched Sentinel-1A and 1B, and together they can provide the InSAR coverage in a 6-day repeat cycle. The studied area was the Upper Silesian Coal Basin in Poland, where the underground coal mining causes continuous subsidence of terrain surface and mining tremors (mine-induced seismicity). The main problem was with overlapping the subsidence caused by the mining exploitation with the epicentre tremors. Based on the Sentinel SAR images, research was done in regard to the correlation between the short term ground subsidence range border and the mine-induced seismicity epicentres localisation.
\end{abstract}

\section{Introduction}

The Upper Silesian Coal Basin (USCB) is located in the south of Poland. It is known as the biggest active area of black coal mining in Europe. As a result of underground (mostly longwall) mining, the surface is susceptible to continuous deformations creating a subsidence area. The subsidence is a continuous process that occurs because of and alongside an excavation process. Additionally the Upper Silesian Coal Basin is known for its complicated geological conditions, thus making it one of the most seismically active mining areas in the world. Seismic investigations performed between 1974 and 2005 registered over 55900 mining related tremors of energy $\mathrm{E} \geq 105 \mathrm{~J}$ (local magnitude $\mathrm{ML} \geq 1.5$ ) [1]. On account of a constant decrease in mining activities since 1995, a constant reduction in the number of tremors was reported. However, since the excavation process currently covers deeper parts of coal deposits. tremors that occur are of higher energies. The occurrence of some of the tremors not only causes a lot of expensive damage to surface constructions and buildings but also affects underground mining infrastructure (excavation, shafts, drafts, etc.).

The mining tremor is a short-lasting, hard to analyse episode. Its epicentre almost always originates within the subsidence area. On account of that, a hypothesis was formed stating that high energy tremors may result in abrupt land subsidence caused by sudden energy releases within rock mass body. This hypothesis was proven with various land surveying works done in the area of an underground cooper excavation (LGOM - Lower Silesia region in Poland) [2]. In the mentioned area, typical gradient of subsidence was 3 to $4 \mathrm{~mm}$ per day [3]. However, in the days following strong tremors, it reached $119 \mathrm{~mm}$ per day. Daily measurements performed on survey lines have proven to be extremely expensive. Typically, this kind of survey is performed once a year, however, in some cases it is necessary to conduct them on some lines once every 6 months. It is easy to notice that this kind of data does not provide continuous monitoring of small elevation changes of an area. On account of that, in between 2002 and 2005 a scientific investigation of possible use of the SAR interferometry of LGOM area was performed [4]. The aim was to perform the monitoring of short term increase in height change of the subsidence area. The results of these studies showed that, for 2002-2005 period, available satellite data imaging is not frequent enough to describe effects of tremors that occur often. At that time, data from the Envistat-1 and ERS 2 satellites had minimum time interval of available data at 35 days. A large number of tremors (up to four) observed every month in a single subsidence area prevented from creating a proper way of analysing and monitoring subsidence area that originated from mining tremors. In 2011, with the use of the PSInSAR method, scientific research was conducted on the correlation between ground subsidence and mining induced seismicity within the USCB [5]. Based on long term observation, the correlations was proved.

Mine tremors are divided into two types: 1) the first type of tremor is directly connected with mining

\footnotetext{
* Corresponding author: artkraw@agh.edu.pl
} 
operations, 2) the second one, which is the seismicity induced by mining, is strongly affected by local geology and tectonics, and interaction between mining, lithostatic and residual tectonic stress on regional level and scale. They usually occur at some bigger distance from mining face and are generally connected to the geological discontinuities [6]. Mining exploitation affects on terrain surface by continuous deformation caused by the subsidence area over exploitation panel.

The aim of the study presented in this article is to evaluate the possibility of recording the short term subsidence caused by mining activities and tremors based on the SAR interferometry. All data should be correlated in time and space. All analyses will be performed with open access data.

\section{Area of research and source data characterisation}

The studied area for this article is the Upper Silesia Coal Basin (USCB), covering about 5,400 square kilometres. Significant part of the area lies within the borders of Poland (4,500 square kilometres), however, it partly reaches beyond them, into the northeastern territory of Czech Republic. The black coal excavation in this region started about 200 years ago and as at 31.12.2013 the resources were assessed at 51 million tons. The excavation is currently done by 21 underground mines. The estimated terrain subsidence caused directly by mining activities is 800 square kilometres.

The first data source used for this study was obtained from the Synthetic Aperture Radar (SAR-C) placed on the Sentinel-1A and 1B satellites. The Sentinel missions are part of the EC (European Commission) Earth observation programme - Copernicus. The European Space Agency (ESA) is in charge of the technical development and maintenance of the mentioned satellites. A repeat interval (also called a revisit time) of the Sentinel satellites is 12 days, but since 2 satellites occupy opposite sides of their orbit (angular distance of 180 degrees), data of the same area are available in 6 days intervals [7]. On account of the Copernicus agenda, all SAFE (Standard Archive Format for Europe) data are available for the public free of charge.

The second data set used for this study is information on mining tremors occurrence. They were obtained from the stations of the Upper Silesian Seismological Network operated by the Central Mining Institute. Data from this source cover the area of about 2000 square kilometres [8]. The seismological network consists of 15 stations. Basing on various data sets gathered by these stations, basic seismological parameters are calculated. An available data bank provides information on the time of dynamic even (tremor) occurrence, its energy, the magnitude, the name of the mine involved and the epicentre coordinates. It is important to mention that energy of tremors is given in M (magnitude) instead of J (Joule - from International System of Units).

Maps of mining areas are the third type of data necessary for this project. These data are available via the MIDAS system provided by the Polish Geological
Institute - the National Research Institute (PGI - NRI). Maps of mining concession areas can be downloaded via WMS (Web Map Service). These data allow to connect the subsidence areas to certain mine. Map from Fig. 1 shows the studied area.

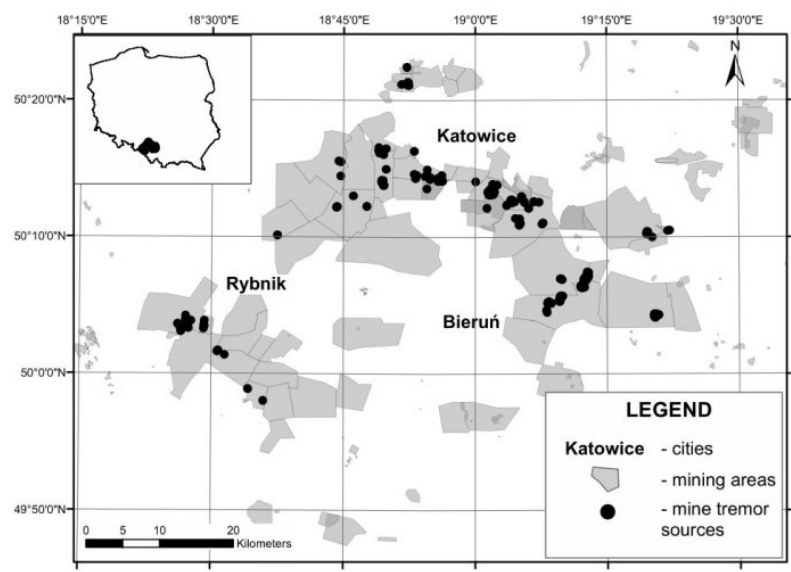

Fig. 1. Studied area including mining areas and epicentres of mining tremors.

\section{Measurement method}

For the purpose of this research, SAR (Synthetic Aperture Radar) type data acquired by Sentinel-1A/B (S1A/S1B) was downloaded from the Sentinels Scientific Data Hub. The European Space Agency (ESA) also provides an open source software, called SNAP, for processing radar images. This software was used for transforming radar into interferometric images. The Digital Elevation Model, used in subtracting topographic phase from the interferogram, was obtained from the SRTM digital elevation data, produced by NASA, with 3 arc second resolution. The size of interferogram pixel is 11.2 metres.

The SAR interferometry is a well-known technique that provides accurate measurements of terrain elevation changes based on the repeated SAR acquisitions $[9,10]$. The technique, as well as its applications and limitations, was described well in literature [11]. The terrain subsidence of the USCB area has been already studied by various teams $[12,13,14,15]$.

The SAR interferograms were transformed into the Polish coordinates system - PUWG 1992. Data on mining tremors, provided in the *.xls format, were geocoded into shape layers and imported into the ArcGIS software. Since these data were provided in the geographic coordinates system, it had to be transformed into the PUWG 1992 system. This supplied the users with sufficient information for further analysis. Fig. 2 shows an example of a S1A/S1B SAR interferogram of the subsidence area within a 6-day cycle. It also shows an epicentre of the tremor, a centre of subsidence area and a distance between those two points. Based on this image, it can be estimated whether the tremor epicentre falls within the area of land subsidence or not. On account of degradation of coherence, which was due to environmental changes, not all subsidence areas were detected [7]. Also, in some cases, not all area parts were 
detected [8], thus not in all cases the distance between the mentioned centres was calculated.

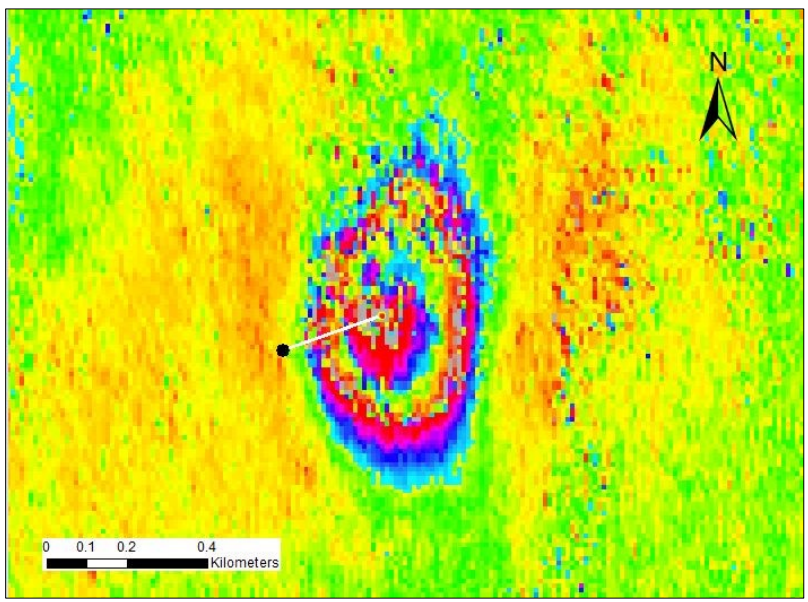

Fig. 2. A SAR interferogram of subsidence area including the distance of $260 \mathrm{~m}$ between epicentre of the tremor (occuring at 2016-11-16) and centre of 6 days subsidence area.

The other issue is estimating the value of subsidence trough registered on interferograms in the form of fringes. The SAR image is not registered vertically, but in the angular range of about 34 degrees. It requires recalculating half of wavelength $2.78 \mathrm{~cm}$ into a single sequence of fringes and then reducing it due to the incidence angle of radar signal. This allows to estimate the maximum value of subsidence in the area showed in Fig. 2 as $23 \mathrm{~mm}$ circa. The problem of estimating the values of subsidence registered on interferograms is a separate research issue and it was not analysed in this article.

\section{Conducted experiments and results discussion}

The time frame of this study was established between 01.09.2015 and 10.02.2017 and included 528 days. During that time, 303 radar images were acquired by Sentinel-1A and Sentinel-1B. The Upper Silesian Seismological Network registered 318 tremors with the magnitude higher than $2.5 \mathrm{M}$. Unfortunately, from 01.09.2015 to 27.09.2016, only the data from Sentinel-1A were available, limiting the interferograms to a 12-day repeat cycle.

Because of the unfavourable land cover (woodlands, agriculture etc.) and the fact that small energy (up to $2 \mathrm{M}$ ) tremors usually do not cause significant damage in mining infrastructure, only 41 areas were selected for further analysis. For selected areas, the $40 \mathrm{SAR}$ scenes were chosen and processed into interferograms. After analysing 41 tremors, in case of 22 of them, it was possible to link them with the subsidence areas on interferograms. In case of the other 19, it was impossible to perform the analysis because of the coherence loss, most likely caused by atmospheric conditions. Furthermore, within the 22 correctly located subsidence areas, only 13 were coherent enough to allow estimation of its centre and the measurement of the distance from the centre to the tremor epicentre. For the purpose of this article, we defined the geometrical method for selecting tremors by the border of the subsidence area. The second parameter is the distance between the epicentre of tremor and the centre of the subsidence area.

The border for a 6-day subsidence trough can be easy detected from the InSAR image. This area includes the part of rock mass that loses support and sags to fill the void beneath the longwall black coal exploitation system. The mechanism progresses from the coal seam towards the surface and affects the surface in a larger area than the area of the extracted panel of coal that is undergoing the settlement. The subsidence is typically lesser than the thickness of coal extracted underground and the resulting border of subsidence trough is the maximal extend of the rock mass deformation caused by the longwall exploitation system.

Based on the border of subsidence trough, three points and two distances were defined. Both of them are presented on Fig 3. There are: 1) cs - the centre of subsidence trough, 2) sb - the border of the subsidence 3) e - the tremor of the epicentre. The line connects the epicentre with the subsidence. The distance will be measured along this line.

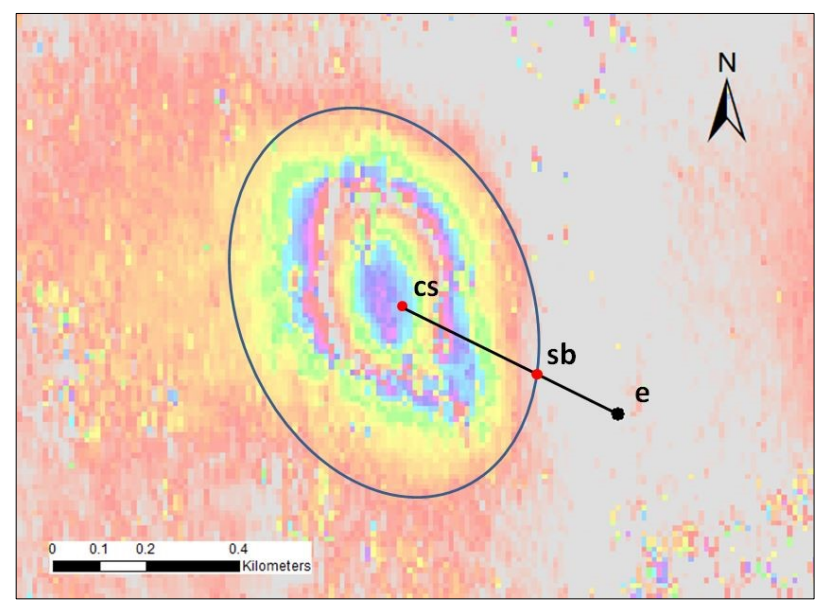

Fig. 3. Proposed geometry method of relation interpretation between centre of subsidence area and epicentre of tremor.

Table 1 presents all the tremors, localised subsidence areas and mines which they refer to. One of the most interesting observations derived from these data is the relationship between interferograms times and the rate of success in finding the subsidence areas. Within 41 interferograms only 6 had temporal baseline (Btemp) of 6 days, the other 25 had Btemp of 12 days or longer. In case of the 6-day repeat cycle, 11 areas were located and also 11 areas where located within the 12-day or longer repeat cycle. This proves $20 \%$ better efficiency of the shorter, 6-day repeat cycle. In regard to the correlation between the placement of the epicentre of the tremor and the centre of the subsidence area, only 7 were beyond the subsidence area (within the 22 which were subjected to the analysis). Out of the 13 measured cs-e, 9 were qualified as within the subsidence area and 4 outside. 
Table 1. Tremors data collation.

\begin{tabular}{|c|c|c|c|c|c|c|}
\hline 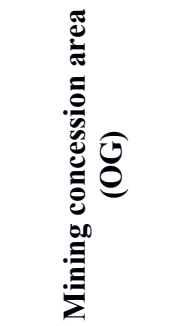 & $\bar{\Sigma}$ & 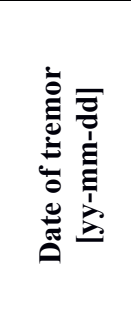 & 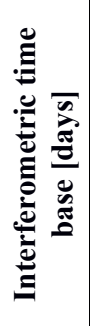 & 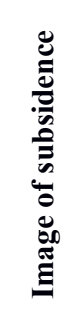 & 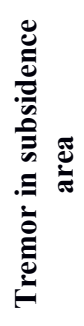 & 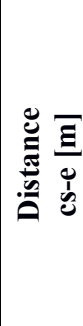 \\
\hline \multirow{6}{*}{ Libiąż IV } & 3.8 & $15-09-30$ & 12 & NO & & \\
\hline & 3.8 & $15-11-18$ & 12 & $\mathrm{NO}$ & & \\
\hline & 3.7 & $15-10-20$ & 12 & $\mathrm{NO}$ & & \\
\hline & 3.1 & $15-10-10$ & 12 & NO & & \\
\hline & 2.5 & 16-11-18 & 6 & YES & YES & 220 \\
\hline & 2.5 & 16-11-18 & 6 & YES & YES & 230 \\
\hline Bytom III & 3.5 & 16-06-03 & 12 & YES & YES & \\
\hline \multirow{7}{*}{ Lędziny I } & 3.4 & 15-09-15 & 12 & NO & & \\
\hline & 3.0 & 15-09-25 & 12 & YES & & \\
\hline & 3.0 & $15-10-08$ & 12 & NO & & \\
\hline & 2.9 & 15-09-08 & 12 & NO & & \\
\hline & 2.9 & $15-11-24$ & 12 & $\mathrm{NO}$ & & \\
\hline & 2.9 & 17-01-14 & 6 & $\mathrm{NO}$ & & \\
\hline & 2.5 & 16-12-22 & 6 & YES & YES & 210 \\
\hline \multirow{8}{*}{ Rydułtowy I } & 3.3 & $16-06-21$ & 24 & YES & YES & 300 \\
\hline & 3.1 & $16-12-01$ & 6 & NO & & \\
\hline & 3.1 & $16-12-01$ & 6 & NO & & \\
\hline & 3.1 & $16-12-01$ & 12 & NO & & \\
\hline & 3.0 & 16-08-19 & 12 & YES & NO & \\
\hline & 2.9 & 15-09-11 & 12 & NO & & \\
\hline & 2.8 & 15-09-08 & 12 & YES & NO & 400 \\
\hline & 2.5 & 15-11-18 & 12 & NO & & \\
\hline Radlin I & 2.5 & 16-08-18 & 12 & YES & YES & 140 \\
\hline Szczygłowice & 3.0 & $16-04-27$ & 12 & NO & & \\
\hline \multirow{12}{*}{ Bieruń II } & 3.0 & 16-11-03 & 6 & YES & NO & 350 \\
\hline & 2.9 & 16-04-30 & 12 & YES & YES & 100 \\
\hline & 2.9 & $16-05-17$ & 12 & NO & & \\
\hline & 2.9 & 16-11-16 & 6 & YES & NO & 260 \\
\hline & 2.9 & 16-11-16 & 6 & YES & NO & 280 \\
\hline & 2.9 & $16-11-21$ & 6 & YES & YES & 90 \\
\hline & 2.9 & 16-11-21 & 6 & YES & YES & 130 \\
\hline & 2.7 & $16-12-13$ & 12 & YES & YES & 210 \\
\hline & 2.7 & $16-12-13$ & 6 & NO & & \\
\hline & 2.5 & $15-09-22$ & 12 & YES & & \\
\hline & 2.6 & $15-10-17$ & 12 & YES & & \\
\hline & 2.5 & $16-12-01$ & 6 & YES & & \\
\hline Bielszowice & 3.0 & 17-01-21 & 6 & NO & & \\
\hline \multirow{2}{*}{ Zabrze I } & 2.9 & $16-12-20$ & 6 & YES & NO & \\
\hline & 2.5 & $15-09-17$ & 12 & YES & NO & \\
\hline \multirow{2}{*}{ Niedobczyce } & 2.8 & 16-12-09 & 6 & NO & & \\
\hline & 2.8 & 16-12-09 & 12 & YES & & \\
\hline
\end{tabular}

The average distance for these 4 instances was 322.5 $\mathrm{m}$ and the average cs-e for the other 9 was at $181 \mathrm{~m}$. For 4 outside events, distances between the edge of the subsidence area and both centres were measured. The edge of the subsidence area identified on interferograms was named $\mathrm{sb}$ (for the purpose of this study). This indicates two new definitions: cs-sb - the distance between the centre of the subsidence area and its edge, and sb-e - the distance between the edge of the subsidence area and the epicentre of the tremor. Further analysis showed that only in the area of the OG Rydultowy I a tremor of $2.80 \mathrm{M}$ magnitude can be qualified as miningtectonic since cs-e is $400 \mathrm{~m}$, cs-sb is $250 \mathrm{~m}$ and sb-e is 150 $\mathrm{m}$. In case of the other three tremors, sb-e distance was only 10 to $30 \mathrm{~m}$ and its value limits interpretation making their origin undefined.

Based on this research, we can divide all tremors into two main categories - tremors inside subsidence area and outside subsidence area.

\section{Conclusion}

These studies proved that the InSAR technology can be used to divide tremors induced by mining into two categories. The first category tremors are within the border of the six days subsidence trough and the second category is outside the border of the subsidence. However, it is important to mention at this point, that these categories cannot be directly linked to the tremor types classification done by seismologists.

The seismology definition of the first type of mining tremors defines the existence of the direct influence between the underground mining operations and the occurrence of the mining tremor [6]. The underground mining operations are determined by defining the current position of the face of excavation at the moment of the mining tremor occurrence, and the measure of these is the distance between the tremor epicentre and the face of excavation. However, the definition does not indicate how to determine the border distance for which the mining tremor can be considered as directly related to the face of excavation and for which cannot.

Using radar interferometry, it is possible to determine the border of the direct influence of the underground mining operations to the terrain surface, which appeared on this surface during 6 days of the excavation. If the mining tremor occurs within these 6 days, 3 locations of the face of excavation should be considered. The first day is the day of the first SAR image. The next position of the face of excavation shall be marked on the day of the mining tremor and the third one is marked on the day of the second SAR imaging.

The 6-day progress of the face of excavation generates the rock mass deformation whose range is illustrated on the interferogram in the form of the subsidence trough. The external border of the subsidence trough is thus the border of the direct influences of the underground mining operations. This allows us to assume that the epicentres of the mining tremors registered outside this border are not of the first type because they are not directly related to the mining works in face of excavation. The proposed method of classifying categories of the mining tremors, in relation to the definition of tremor types, can significantly simplify the interpretation of the mining tremors. 
Of course, during the interpretation of tremors, the distance between the epicentre of tremor (e), the subsidence border $(\mathrm{sb})$ and the centre of the subsidence (cs) should also be taken into account. For example, if a tremor occur with the $\mathrm{cs}-\mathrm{sb}$ distance being the same or smaller than the sb - e distance, we can be sure that the tremor can be treated as the second type. On the other hand, if the sb-e distance is from $1 \mathrm{~m}$ to about $50 \mathrm{~m}$, it does not determine the type of tremor. This is due to the fairly low accuracy of the location of the tremor epicentre. However, it requires further studies on that topic.

The next, more general conclusion based on classical observation on leveling lines [2] and interferometry research, shows that the mining induced tremors (the first type) and the subsidence should be treated as one integrated process of terrain and rock mass deformation.

Another problem, which should be taken into consideration, is an interval in days between the SAR image acquisitions which reached the 6-day repeat cycle with the Sentinel satellite constellation. In the USCB condition, the mining tremors with the magnitude bigger than $2 \mathrm{M}$ occur even every 2 days. Of course, most of them occur in different locations. In the analysed period, there were not any two tremors in the same location within 6 days. However, the emergence of this situation cannot be excluded in the future. Therefore, in the future, a matter of interest should be in obtaining SAR data that have even shorter repeat cycle, for example 2-3 days..

Despite difficulties that occur during acquisitions of SAR data (Btemp 12 days with respect to 6 days) and the coherence of interferograms for the studied subsidence areas, it was proven that this method could be used for monitoring the surface consequences caused by the underground coal mines. The visible correlation between the tremor epicentres and the centre of the subsidence area indicates the need for further scientific exploration of this subject. It should be mentioned that the launching of Sentinel-1B to the orbit significantly improved the data availability for this study.

Based on the described research, the subsidence areas for the further analysis were selected. Best results, in regard to quality of interferograms, were recorded for the OG Bierun II area. This area is known for its susceptibility to tremors and also the land cover is favourable for the SAR interferometry, which can bring potential economic profits for such areas [16]. The next step of this study will be gathering geological, geotechnical and detailed mining data which allows to analyse the epicentre of the tremor in regard to excavation front movements. This analysis will also include the lithological and tectonic model correlation with the tremors occurrence.
Special thanks to the dr. Z. Perski (PGI-NRI) for all the necessary information's, constructive criticism and suggestions.

\section{References}

1. K. Stec, Geophys J Int 168(2), 757-768 (2007)

2. E. Popiołek, J. Ostrowski, J. Czaja, J. Mazur, 10th FIG International Symposium on Deformation Measurements, 77 (Orange, California, USA, 2001)

3. A. Krawczyk Z. Perski, 11th International Congress of the International Society for Mine Surveying 2, 209 (Cracow, Poland, 2000)

4. E. Popiołek, H. Marcak, A. Krawczyk, Warsztaty 2006: Natural hazards in mining, 339 (2006)

5. K. Mirek, J. Mirek, Polish Journal of Environmental Studies 20 (4A), 253 (2011)

6. J. Gibowicz, A. Kijko, An Introduction to Mining Seismology (Academic Press Inc., San Diego, USA 1994)

7. ESA, https://directory.eoportal.org/ (March 2017)

8. USSN, http://www.grss.gig.eu/en/ (March 2017)

9. K. Mirek, Polish Journal of Environmental Studies 18 (3A), (2009)

10. X. Li, D. Liu, H. Song, R. Chen, H. Li, Journal of Electronics 31 (5), 441 (2014)

11. A.K. Gabriel, R.M. Goldstein, H.A. Zebker, Journal of Geophysical Research: Solid Earth and Planets 94(B7), 9183 (1989)

12. Z. Perski., D. Jura, Earth Observation Quarterly 63, 25 (1999)

13. K. Mirek, J. Mirek Polish Jour. of Environ. Stud. 25 (5A), 57 (2016)

14. M. Przyłucka, G. Herrera, M. Graniczny, D. Colombo, M. Béjar-Pizarro, Remote Sensing 7 (5), 5300 (2015)

15. S. Porzycka-Strzelczyk, H. Malik, J. Strzelczyk, SGEM 2015 Conference Proceedings 1,1075 (2015)

16. K. Przeździcki, J. Zawadzki, Systemy wspomagania $w$ inżynierii produkcji 1 (13), 11 (2016) 